\title{
FILOSOFIA
}

\section{El Segundo Centenario de Goethe}

Discurso de orden pronunciado por el Dr. Ma. riano Ibérico Rodríguez, en la ceremonía de incorporación eomo Catedrático "Honoris Causa' del Profesor Tritz Joachim von Rintelen.

Señor Decano de la Facuitadrede Letrás:

Señoras:

Señores:

Con el más vivo agrado y oumpliendo honroso encargo de läi Facultad de Letras, vengo a decir estas palabras de saludo y cordial homenaje al profesor doctor Frifildadhorternardelentetrangtivo de su incor-

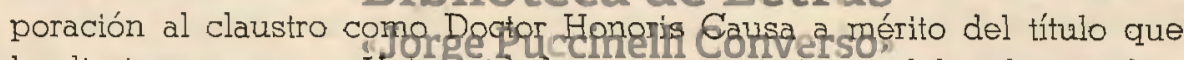
le discierne nuestra Universidad en reconocimiento del valor intelectual de su obra y: especialmente, como muestra de admirativo aprecio por la forma brillante con que contribuye al éxito de nuestra conmemoración goethiana. Saludo y homenaje que, en la persona de su distinguido representante, tributamos igualmente a la inmortal cultura alemana, a la que tanto debe la vida del espíritu y que, con ocasión de este glorioso centenario, ofrece al mundo uno de sus más elevados títulos a la gratitud universal.

El doctor von Rintelen, en unión de Nicolai Hartmann y de otros entinentes pensadores, forma parte del Curatorium que es la institución directiva de las Sociedades Alemanas de Filosofía; edita con Bertrand Russell la "Revista para la Investigación Filosófica"; ha presidido el último Congreso Alemán de Filosofía, y es aubr, entre otros importantes trabajos, de las siguientes obras: "Lo Demoníaco de la Voluntad"; "Nuestro Lugar Espiritual a la luz de la Cultura Cristiana"; "El Concepto de Valor en el Desarrollo del Espíritu Europeo"; "Goethe, Hombre Occiden- 
tal". A su activiciad de escritor une la de su labor docente como profesor de filosofía primero en Bonn y en Munich y al presente en la antigua y nueva Universidad de Maguncia. Actividades y obras en que se revela, junto con una profunda visión de las realidades y de los problemas espirituales, un admirable sentido de elevación y de emoción humana y metafísica al buscar los senderos de perfección y salvación.

En el mundo de discordia interna y de caótica confusión en que vivimos, busquemos dice el prolesor von Rintelen, las posiciones fundàmentales, porque sólo partiendo de ellas podremos superar el infierno de nuestros días. Y esas posiciones que son al mismo tiempo bases y direcciones, logros y posibilidades se fundan a su vez en la gran convicción del espíritu, del verdadero espíritu que al par que penetra y transfigura todas las formas de la naturaleza y de la vida las trasciende en cuanto se eleva por encima de toda contingencia como reino de las esencias y de los valores leternos. Esta concepción del verdadero espíritu como un mundo de yerores aternos inalcanzables por el mero formalismo intelectualista y cccesible tan solo por un movimiento total de la persona que incluỹe la inflita sudiduría del corazón de que hablaba Pascal, le permite aqprofesol von Rintelen formular dezisivos reparos a las concepciones moterhas gue pretenden, sustituír al verdadero espíritu, que es a la vez trascendolite y vivo, con formas infieriores o con modos negativos de la realidad humana.

Tres manifest Bibadi ortebales Es unetelnastos tiempos esta des-

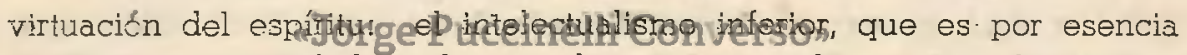
cuantitativo y nivelador, el puro dinamismo vitalista que culmina con la voluntad de poderío enemiga del verdadero espíritu que es cualidad, orden, distinción de valores y por lo tanto dominio propio y libertad tanto interna como externa de la persona individual y, en fin, la filosofía de la existencia finita que cierra de modo inexorable toda posibilidad de trascendencia. Von Rintelen analiza con penetración todas esas formas en que el espíritu decae y se pierde. Aquí sólo quiero detenerme en su profunda crítica de las filosofías de la finitud que con el nombre de existencialismo, han adøuirido en nuestros tiempos una tan sintomática y extraordinaria resonancia. Esas filosofías configuran la realidad ziu. mana en la dimensión de la pura temporalidad, de la pura inmanencia, y no ofrecen a su angustia otra posibilidadi que la desesperación y la incurable tristeza. Frente a esta actitud, piensa von Rintelen que urge oponer a la negatividad de la desesperación y de la angustia, las actitudes positivas y creadoras de la confianza, de la alegría y del amor, que, im- 
plicando la admisión de un mundo de valores superiores y absolutos, abren a la trascendencia un horizonte infinito y liberan así la vida de la tétrica y abandonada limitación en que se ahoga. Hay que volver los ojos a la luz y asumir con la alegría y el amor la responsabilidad y la gracia de la vida.

Con amorosa comprensión y vasto conocimiento aprecia el legado de la antigüedad y el hondo sentido de la vida y de la cultura cristianas. "Todo lo que nuestro espíritu descubre como bueno y valioso" escribe "puede, en sentido agustiniano, ser considerado como un reflejo del valor supremo". De manera que el hombre, limitado como es, puede reflejar en su vida algo infinito y divino. Con lo cual el pensamiento y la vida cristianos instituyen en la jerarquía de las cosas y de los actos la fecunda unidad en que lo creado se eleva, sin destruirse, al reino superior de la gracia.

Apreciando en conjunto la filessofí del doctor von Rintelen yo diría que es una filosofía anagógica, que lntergreta la existencia en términos de elevación y plenitud como vofación de o profundo hacia las esferas luminosas del espíritu.

Mas he aquí que la evecafión do la luz, de la alegría y del amor, nos trasportan al círculo de da nagis goethiana.

Y así volvemos a Goethe euy figura imanta en estos días todos los pensamientos, cuya prosencia llena de invisible prestigio el espacio

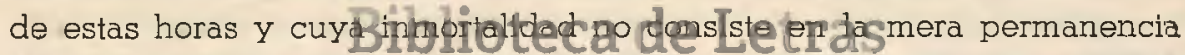
de su imagen en el Panteón de la cultira sino en la eterna virtualidad de su obra, inagotable cono la naturaleza que el tanfo amaba, y, en consecuencia, propicia a estimular por modo interminable el trabajo y el deleite de la meditación.

No entra en las intenciones de este discurso hacer un análisis de la obra de Goethe que distinguidos conferencistas realizan con pleno conocimiento y profundidad. Y así sólo me referiré a los aspectos que considero ejemplares como acabadas expresiones del pensamiento intuitivo y como nobles formas de la actitud vital ante el problema invisible $\mathrm{y}$ el esplendor visible del cosmos natural y humano.

Goethe es el grande hombre de la totalidad, el gran maestro de la armonía, el gran orquestador de todas las voces de la vida. Su genio no se movía en la atmósfera de las puras abstracciones inertes, tampoco se abandonaba a la mera impulsividad caótica. Y el milagro, el prodigio de su obra como realización espiritual consistió en que pudo absorber lo dinámico y torrencial sin congelarlo, en que pudo pensar $\theta$ 
imaginar con plástica y acabada pureza sin ahuyentar de sus creaciones el anhelo infinito de la eterna, inexhaustible posibilidad. Integración de lo apolineo y lo dionísíaco, con el predominio final de la luz y de la forma sobre la oscuridad y la discordia.

La totalidad que amaba Goethe y en cuya riqueza participaba con entusiasmo y plenitud su maravilloso espíritu era una totalidad de vi$\mathrm{da}$, que Goethe consideraba esencialmente como una actividad de configuración y de forma que, por una parte lo instaba a buscar la forma arquetípica, primordial de toda vida y por otra le hacía sentir y pulsar las palpitaciones profundas de la vida en la contemplación de las formas. Su teoría de los fenómenos primordiales de sentido eminentemente platónico, su intuición de la polaridad, su concepción de la metamorfosis como tendencia de la vida a superar las formas ya acabadas organizándolas en una escala ascensional le permitieron a Goethe contemplar la totalidad orgánica de lo real cormo una unidad jerárquica propuesta a la admiración y a la elevasión del hombre.

Este sentido de la vita como actizadad de configuración inspira así su concepción de la aeturaleze, come su concepción de la productividad espiritual en el ámblo de la cultura. Concepción que en la vida y en la obra de Goetho tiene la realización más cumplida y fecunda. La forma, o si queremas lo apolíneo, es aportado por la tradición antigua cuyo mensaje no únicamente literario sino palpitante y presente lo recogió el p\&iblolidteckarieheia detressjaje a Italia; lo que Nietzsche llamaría mís tarde lo dionisízco estaba representado por las tensiones y las virtualidades de finacion romantica que Goethe, alemán, vivió con intensidad y hondura. Constituyendo el todo "el conjunto de la obra' algo así como la expresión paradigmátíca de la plenitud humana en su noble, alegre y erótica aceptación de la vida.

"Goethe se vuelve constantemente", dice Paul Valery, "como una de esas plantas que él ama hacia lo más' luminoso y cálido del instante' . Y no es que él ignorara la profundidad abisal de la vida. Sabemos que la conocía, pero esa experiencia se incorparaba en el movimiento o, si queremos expresarnos así, en el tropismo general de su espíritu hacia la luz y lo alto.

Acentuando el sentido de ejemplaridad humana y superación salvadora de la síntesis entre hondura y altura escribe el doctor von Rintelen: "El hombre goethiano vive conscientemente los abismos del alma, conoce igualmente las contradicciones abismales que pueden amenazar la existencia. Sin temor encara los tenebrosos poderes indecibles; perio. 
es sólo para emprender con mayor profundidad la vía libre del ascenso espiritual".

En un mundo dividido y caótico la evocación del pensamiento goethiano nos trae la enseñanza de la armonía y del orden, en la crisis donde naufragan juntamente la individualidad y la universalidad, Goethe nos enseña el valor universal de lo individual; en medio a la angustia y a la desesperación del presente nos muestra Goethe el valor de la alegría, de la esperanza y del amor. Volvamos pues la mirada a estas claras y cálidas verdades de la revelación goethiana.

Señor profesor von Rintelen:

Nos habóis traído un mensaị de la más noble calidad. Vuestras reflexiones personalss sobre problemas que por afectar las raíces mismas de nuestra cultura nos áectan slstancialmente a todos, señalan a nuestra inquietud altas direccienes posibilidades. Vuestras conferencias sobre Goethe, reafirman nyestra admizoión y amplían la persepctiva de nuesta emocionada con emplazióx. Qe lo agradecemos, y esperamos que estas horas vividas on la consideración de cosas tan altas sean precursoras de otras jornddas felices que bajo el signo de la paz y la esperanza, podamos consegrar al trabajo por el progreso y la gloria del espíritu.

\section{Biblioteca de Letras "Jorge Puccinelli Converso"}

